\title{
Applicability of Source Water Source Heat Pump System in Hot Summer and Warm Winter Area
}

\author{
Weizhou Hu \\ College of Mechanical Engineering, Guangxi University, Nanning, China \\ Email address: \\ lisquence@outlook.com
}

To cite this article:

Weizhou Hu. Applicability of Source Water Source Heat Pump System in Hot Summer and Warm Winter Area. International Journal of Mechanical Engineering and Applications. Vol. 7, No. 5, 2019, pp. 123-130. doi: 10.11648/j.ijmea.20190705.11

Received: November 13, 2019; Accepted: November 14, 2019; Published: November 25, 2019

\begin{abstract}
Water source heat pump with relatively stable surface water as heat transfer medium is a new type of energysaving and temperature-regulating equipment. Its refrigeration and heating coefficients are 3.5-4.5 high. Water source heat pump has been widely used in refrigeration and heating of buildings in many foreign countries as an important energy-saving equipment. The number of water source heat pump energy stations has increased by $10 \%$ annually. The traditional coal pans used in large greenhouses in China often have some problems, such as low thermal efficiency, high energy consumption, high pollution and difficult cooling in summer. It is very helpful to use water source heat pump technology reasonably to solve these problems. In this paper, the water source heat pump air conditioning system is used in public places for experimental testing and research. The operation performance of the water source heat pump energy station is studied through experimental tests, which can provide reference for the popularization and application of the technology in hot summer and warm winter areas. The research contents of this subject are as follows: Under the rated operating conditions of the water source heat pump air conditioning system; the operation performance of the heating system is analyzed; Understanding and mastering the operation performance of water source heat pump air conditioning system, and comprehensively analyzing the stability and energy efficiency ratio of the system; The main problem to be solved is that it can not only ensure the operation cost unchanged or even reduce, but also improve the heating efficiency of water source heat pump air conditioning system.
\end{abstract}

Keywords: Water Source Heat Pump, Air Conditioning System, Heating Conditioning

\section{Introduction}

\subsection{Research Background}

With the development of science and technology, a series of problems, such as over exploitation of energy, pollution of water resources, rising temperature, destruction of vegetation and so on, have to be solved urgently. So now people also begin to pay attention to the development of green energy, the use of green products, energy-saving and environmental protection equipment, so the water source heat pump system has been more attention and use, and the water source heat pump system is more and more important in daily life. The working principle of the water source heat pump unit is to transfer the heat in the building to the water source in summer; in winter, it extracts energy from the water source with relatively constant temperature, uses the surface water as the refrigerant, uses the heat pump principle to raise the temperature and then transmits it to the building. Generally speaking, water source heat pump consumes $1 \mathrm{~kW}$ of energy, and users can get 4 times or more heat or cooling capacity. Water source heat pump not only overcomes the frost problem of outdoor heat exchanger of air source heat pump in winter, but also has the characteristics of high operational reliability and heating efficiency, which has been widely used in China in recent years. If water can be used as the heat and cold source of air conditioning system, compared with traditional boiler heating, it can effectively reduce energy consumption.

\subsection{Research Status of Water Source Heat Pump Energy Station at Home and Abroad}

The river water source heat pump (rwhp) system of energy station is introduced in reference [1]. Rwhp system is recognized as one of the most promising technologies for energy conservation and sustainable development. In order 
to study the actual operation effect of rwhp system, the energy consumption of heat pump unit, power consumption and distribution energy consumption of various circulating water pumps are analyzed in detail. In reference [2], the application of automatic control technology in sewage source heat pump energy supply station is explained in detail. The automatic control technology can effectively solve the problems of sewage flow monitoring, wide channel heat exchanger equipment fault monitoring, gravity water control, water storage control and other monitoring. It can not only control the operation of process equipment in time, but also meet the requirements of anti-interference, applicability, compatibility, scalability and other aspects of the system. In reference [3], in order to determine the operation effect and optimization measures of the water source heat pump system of the comprehensive energy station, the monitoring of energy supply and geothermal exchange volume on the user side of the ground source heat pump system of an energy station is carried out. The average operation efficiency of the evaluation system is from two aspects of energy storage and supply. The results obtained in the monitoring show that the water source heat pump system stores energy at night, and releases the energy stored at night during the day, so as to provide heat energy. Over the past three years, the average operating efficiency of the system has reached $91.4 \% \sim 112.7 \%$ of the rated cop. It can not only save a certain operating cost and reduce carbon dioxide emissions, but also ensure the efficiency of the whole system. To sum up, with the increasingly mature of water source heat pump technology and the wide application of water source heat pump energy station, scholars at home and abroad have carried out a lot of related research work, and obtained a lot of theoretical and technical research results with great reference value, The main conclusions are as follows: if the water area conditions are sufficient, the use of water source heat pump system can reduce the energy consumption of building cooling and heating. Compared with air source heat pump system, the water source heat pump system has obvious advantages in both operating energy consumption and system energy consumption. Compared with other systems, water source heat pump has great advantages in energy saving and emission reduction in large-scale regional heating and cooling projects in winter and summer. However, there are few researches on the application of water source heat pump in hot summer and warm winter areas. In this paper, the research on the operation performance of water source heat pump energy station is carried out for the typical geographical location and application place of hot summer and warm winter areas office buildings and comprehensive venues in the south of hot summer and warm winter areas.

\subsection{The Main Content of This Paper}

The project is located in Chongzuo City, which is a typical hot summer and warm winter area. The main research contents of this paper are as follows: (1) according to the specific conditions of Chongzuo water source heat pump energy station project, local surface water conditions, climate conditions, specific implementation scheme and other conditions, two working condition design methods are proposed; screw type water source heat pump air conditioning system is used in winter heating working condition, and screw type water source heat pump combined with water-cooled screw type water chiller is used in summer cooling working condition. This paper mainly studies the operation performance of the water source heat pump air conditioning system under the winter heating condition. (2) the air conditioning system of Chongzuo office building and comprehensive venue is composed of screw type water source heat pump unit and water-cooled screw type water chiller. According to the geographical environment of Chongzuo and the characteristics of hot summer and warm winter climate area, a single factor method is used to test the following factors, such as: ambient temperature, lake water temperature, unit operation time and so on, for heating operation in winter The impact of row performance.

\section{Engineering Design of a Water Source Heat Pump Energy Station}

\subsection{Water Source Heat Pump Air Conditioning System Scheme}

Because the specific conditions of the two buildings of Chongzuo culture and Art Center and administrative center are different, there are differences in the heating demand of the two buildings in winter. The heating capacity of cultural and Art Center in winter is $754 \mathrm{kw}$; that of administrative center in winter is $2178.6 \mathrm{kw}$. After analyzing the actual engineering conditions of the project and the impact of other factors such as local climate and environment in Chongzuo, the cold and heat sources of the water source heat pump energy station of the project are the lake water of Longteng lake and West Longteng lake. The heating of culture and Art Center and administrative center of the project is provided by screw type water source heat pump unit.

In winter, the screw type water source heat pump air conditioning system completes the heat exchange with the water of Longteng lake and West Longteng Lake through heat exchanger, and takes out the condensation heat discharged during the cooling in summer as the heating heat. It not only reduces the impact on the water environment of Longteng lake and West Longteng lake, but also greatly improves the energy conversion efficiency. The geographical environment around the project is applied according to local conditions.

\subsection{Water Source Heat Pump Unit and System Design}

\subsubsection{Selection of Water Source Heat Pump Unit}

According to the analysis above, the heating load in winter is far less than the cooling load in summer, no matter in culture and art center or administrative center, so the water 
source heat pump unit should be selected according to the cooling load in summer. According to this scheme, the heating load in winter can also meet the demand and meet the demand.

According to the scheme of water source heat pump air conditioning system, the water source heat pump energy station of this project is composed of screw water source heat pump unit and water-cooled screw water-cooled unit. The water-cooled screw type water-cooled unit is responsible for refrigeration, and the screw type water source heat pump unit has refrigeration and heating as one, which meets the needs of the project. This water source heat pump energy station is designed for two working conditions: cooling in summer and heating in winter. This subject only studies the heating in winter.

The water source heat pump energy station consists of four screw type water source heat pump units and two watercooled screw type water-cooled units. Because each unit has different functions and different power, the unit scheme is selected as follows:

Two screw type water source heat pump units (cooling capacity $739 \mathrm{kw}$, heating capacity $782 \mathrm{kw}$ ) and one watercooled screw type water-cooling unit (cooling capacity $639 \mathrm{kw}$ ) are selected for cooling in the Cultural Arts Center in summer. A screw type water source heat pump unit (cooling capacity $739 \mathrm{kw}$, heating capacity $782 \mathrm{kw}$ ) is selected for heating in winter.

Two screw type water source heat pump units (refrigerating capacity $1136 \mathrm{kw}$, heating capacity $1196 \mathrm{kw}$ ) and one water-cooled screw type water-cooled unit (refrigerating capacity $2132 \mathrm{kw}$ ) are selected for cooling of the administrative center in summer. Two screw type water source heat pump units (refrigerating capacity $1136 \mathrm{kw}$, heating capacity $1196 \mathrm{kw}$ ) are selected for heating in winter.

\subsubsection{System Operation Strategy}

Culture and art center does not need to consider the heating condition of the unit in summer, so it is not described Under the heating condition in winter, at this time, the unit exchanges heat with the lake water and uses the heat taken out for heating. The opening hours of the culture and Art Center are from 7:00 to 12:00 in the morning and from 2:00 to $6: 00$ in the afternoon. The air conditioning water in the system pipe will cool down for 13 hours between 6:00 p.m. and 7:00 p.m. the next day. In order to have heating as soon as the air conditioner is turned on, the system needs to be preheated one hour in advance. Focswater2001c-hl screw type water source heat pump unit is selected.

The administrative center does not need to consider the heating condition of the unit in summer, so it does not describe it. Under the heating condition in winter, at this time, the unit exchanges heat with the lake water and uses the heat taken out for heating. The opening hours of the administrative center are from 8 a.m. to 12 a.m. and from 2 p.m. to 6 p.m. The air conditioning water in the system pipe will cool down for 14 hours between 6:00 p.m. and 8:00 p.m. the next day. In order to have heating as soon as the air conditioner is turned on, the system needs to be preheated one hour in advance. Two focswater3002c-hl screw type water source heat pump units are selected.

\section{Experimental Research and Analysis of a Water Source Heat Pump Energy Station}

The object of this experiment is the water source heat pump energy station composed of the screw type water source heat pump unit and the water-cooled screw type water chiller unit implemented by Chongzuo culture and Art Center building and the administrative center. The system uses lake water as cold (hot) source, heating in winter and cooling in summer. In this paper, we only test and analyze the performance of winter heating operation condition, process, calculate and analyze the measured data for many times, understand and master the operation rules of the system composed of screw water source heat pump unit and watercooled screw water chiller, explore the most reasonable working mode of the air-conditioning system in winter heating operation condition, and discuss No The influencing factors of the same factors and different conditions on the unit energy efficiency ratio and system energy efficiency ratio of the composite system, after analyzing and testing the operation performance of the water source heat pump system, summed up the influencing factors on its operation performance, and provided some help for future experiments and research.

\subsection{Design Experiment Scheme}

\subsubsection{Experimental Method}

For the open surface water source heat pump system of Chongzuo water source heat pump energy station, this experiment adopts the single factor method.

Under the condition of screw type water source heat pump heating, the outdoor environment temperature changes at any time in winter. According to the outdoor environment temperature change and the unit operation time, the experimental test scheme is designed: test the parameters of the water source heat pump system (such as unit current, voltage and other data), and record the unit operation time, lake water temperature and the inlet and outlet medium at the condenser side of the evaporator Mass flow rate. Analyze and process the test data. Combined with various factors, the performance and index of the system are obtained. In the process of the experiment, the debugging of the temperature probe is very important. After the debugging temperature probe is installed, the inlet and outlet temperatures of the evaporator and condenser should be carefully observed. The inlet and outlet temperatures of the evaporator and condenser are the key to judge whether the system is stable or not. Only when the system reaches a stable state, can normal experiment test, research and analysis be carried out. 


\subsubsection{Experimental Scheme}

In winter, the operation data of screw type water source heat pump air conditioning unit, air conditioning circulating pump and water source circulating pump in the water source heat pump energy station are tested. The main test data are: medium flow and medium temperature at the inlet and outlet of evaporator side and condenser side of screw type water source heat pump air conditioning unit, indoor and outdoor temperature, lake water inlet and outlet temperature, screw type water source heat pump The current and voltage of air conditioning unit, air conditioning circulating pump and cooling water circulating pump; the experimental parameters are as follows.

Table 1. Experimental scheme of water source heat pump heating condition in culture and Art Center.

\begin{tabular}{ll}
\hline Experiment item & Parameter range of experimental regulation \\
\hline Medium flow at condenser side $(\mathrm{m} 3 / \mathrm{h})$ & $172.46,176.66,177.79,179.85,181.33$ \\
Medium flow at evaporator side $(\mathrm{m} 3 / \mathrm{h})$ & $238.77,240.73,241.92,242.63,244.61$ \\
Outdoor temperature of culture and Art & $8,9,10,11,12,13$ \\
Center $\left({ }^{\circ} \mathrm{C}\right)$ & $09: 20,09: 40,10: 00,10: 20,10: 40,11: 00,11: 20,11: 40,12: 00,12: 20,12: 40,13: 00,14: 00,14: 20,14: 40,15: 00$ \\
\hline
\end{tabular}

\subsection{Purpose of Experimental Research}

In this experiment, the screw type water source heat pump combined with water-cooled screw chiller is used to test the heating condition of the water source heat pump system in Chongzuo water source heat pump energy station of Guangxi Zhuang Autonomous Region. The influence of different factors on the operation performance of the water source heat pump system is discussed, and the performance characteristics of the water source heat pump system in winter are analyzed Conclusion.

1) Through further analysis and comparison experiments, the operation characteristics and rules of the air conditioning system composed of screw water source heat pump unit and water-cooled screw water chiller are obtained, and the influencing factors on the operation performance of the system are summarized.

2) Further analysis and comparison experiments, sort out the optimal operation mode of the air conditioning system composed of screw water source heat pump air conditioning unit and water-cooled screw water-cooling unit under the heating condition, and provide reference for the design, installation, operation and other aspects of the air conditioning system in the future.

3) Further analysis and comparison experiments show that "the air conditioning system composed of screw type water source heat pump air conditioning unit and watercooled screw type water chiller unit is feasible and green in the hot summer and warm winter area where the surface water quality reaches the standard." This view has been proved. It provides a reference for the promotion and application of the air conditioning system in Chongzuo City.

\subsection{Processing Data}

The early stage of data processing is data collection, which is one of the experimental purposes. By testing and recording the air-conditioning system for a long period of time, a large number of data are collected, but not all of the data are completely correct. Many data have various errors, such as the error of human operation, the error of the instrument itself. Therefore, it is necessary to deal with the data scientifically, so as to analyze the experimental data, understand and master the performance of the air conditioning system in winter heating conditions. The processing of experimental data includes two parts. The first part is to sort out the data collected directly by the instrument, and the last part is to calculate the sorted data and get the experimental results.

\subsubsection{Data Arrangement and Analysis Application in the Early Stage of Experiment}

In the process of experiment, temperature, humidity, flow, current, voltage, power and other data are recorded by human and various experimental instruments. It is inevitable that there are human errors in this process, plus the accuracy errors of the measuring instrument itself. The data collected in the experiment is not completely accurate. We need to correct it to some extent. The methods are as follows:

In winter heating condition, for $\mathrm{n}$ sampling values of the same parameter, the arithmetic mean value formula of the sampling values is as follows:

$$
\bar{x}=\frac{\sum x}{n}
$$

The mean square deviation formula of each sample value is as follows:

$$
\sigma=\sqrt{\frac{\sum(x-\bar{x})^{2}}{n}}
$$

The outliers measured in the experiment are eliminated by three criteria as follows:

$$
(x-\bar{x})>3 \sigma
$$

\subsubsection{Later Stage Calculation}

The main content of later calculation is to calculate the energy ratio. The hard index of energy efficiency conversion rate of equipment is energy efficiency ratio. The conversion ratio of energy to heat is called the energy efficiency ratio. The higher the energy efficiency ratio is, the higher the conversion efficiency of the equipment is; otherwise, the 
worse the conversion efficiency of the equipment is.

Heating capacity of water source heat pump host $\mathrm{Q}_{\mathrm{m}}(\mathrm{kW})$

$$
\mathrm{Q}_{\mathrm{m}}=\frac{\mathrm{C} \cdot \rho \cdot \mathrm{v} 1 \cdot(\mathrm{t} 0-\mathrm{ti})}{3600 \times 1000}
$$

$\mathrm{Q}_{\mathrm{m}}$ - Heating capacity of main engine $(\mathrm{kW})$

$\mathrm{C}$-Specific heat capacity of water, which is 4.1868 $\left(\mathrm{kJ} / \mathrm{kg} \cdot{ }^{\circ} \mathrm{C}\right)$

$\rho$-Average density of water $\left(\mathrm{kg} / \mathrm{m}^{3}\right)$

t0 - Outlet water temperature of main engine condenser $\left({ }^{\circ} \mathrm{C}\right)$

ti-Water inlet temperature of main engine condenser $\left({ }^{\circ} \mathrm{C}\right)$

v1 - Circulating water flow at condensation side of main engine $(\mathrm{m} 3 / \mathrm{h})$

Actual power $\mathrm{Q}_{\mathrm{a}}(\mathrm{kW})$ :

$$
\mathrm{Q}_{\mathrm{a}}=\frac{\mathrm{U} \cdot \mathrm{I} \cdot \cos \varphi \cdot \sqrt{3}}{9 \times 1000}
$$

I-Sum of three-phase current (A)

$\mathrm{U}$-Sum of voltage $(\mathrm{V})$

$\cos \varphi$-Power factor, which is 0.76

Energy efficiency ratio of lake water heating:

$$
\begin{gathered}
\mathrm{COP}=\frac{\mathrm{Q}}{\mathrm{Q} 1} \\
\mathrm{COP}=\frac{\mathrm{Q}}{\mathrm{Q} 1+\mathrm{Q} 2+\mathrm{Q} 3}
\end{gathered}
$$

Q- Heating capacity of air conditioning heat pump host $(\mathrm{kW})$

Q1-Adjusting the input power of heat pump host in heating time and space $(\mathrm{kW})$

Q2-Power of water source circulating pump during heating $(\mathrm{kW})$

Q3-Power regulation of circulating pump in heating time and space $(\mathrm{kW})$

\section{Operation Performance Analysis}

In the middle of January in Chongzuo City, the outdoor temperature changes in the range of $6^{\circ} \mathrm{C} \sim 12^{\circ} \mathrm{C}$, which is in line with the climate conditions of using water source heat pump for heating and opening the system to test the heating conditions. The heating system uses the water of Longteng Lake as the heating energy. The heating heat load of the administrative center is $2178.6 \mathrm{kw}$, and there are two focswater3002c-hl screw water source heat pump units with the heating capacity of $1196 \mathrm{kw}$, two god100-32 air conditioning circulating pumps and two god125-32 water source circulating pumps. At this time, close the valves V3, $\mathrm{V} 4, \mathrm{~V} 5$ and V6, and open the valves V1, V2, V7 and V8. The basic working principle is to use the single factor method to analyze the heating conditions, record the lake water flow at the evaporation side of different screw type water source heat pump air conditioning units, the air conditioning water flow at the condensation side of water source heat pump air conditioning units, and test the impact of these two factors on the operation of screw type water source heat pump units The screw type water source heat pump system in the lake water source heating performance analysis, to develop a more ideal operation program.

\subsection{The Influence of Circulating Medium Flow on Screw Type Water Source Heat Pump System}

It can be seen from the characters we have received that under the heating condition of the system, the fluctuation range of the inlet medium temperature at the evaporator side is very small, and the outlet medium temperature at the evaporator side increases with the increase of the flow rate. When the medium flow rate is $240.73 \sim 244.61 \mathrm{~m}^{3} / \mathrm{h}$, the outlet medium temperature at the evaporator side tends to be stable. The medium temperature difference between the inlet and outlet of the evaporator side of screw type water source heat pump air conditioning unit decreases with the increase of the medium flow rate at the evaporator side.

When the medium flow at the evaporator side is $238.77 \mathrm{~m} 3 / \mathrm{h}$, the medium temperature difference at the inlet and outlet of the evaporator side is $1.6^{\circ} \mathrm{C}$,

When the flow rate of the medium at the evaporator side is $240.73 \sim 244.61 \mathrm{~m} 3 / \mathrm{h}$, the temperature difference between the inlet and outlet of the medium at the evaporator side is about $1.5^{\circ} \mathrm{C}$, which tends to be low and stable.

It can be seen that at the same time, the energy efficiency ratio of the air conditioning unit increases with the increase of the flow at the evaporator side. When the medium flow rate at the evaporator side is $238.77 \mathrm{~m} 3 / \mathrm{h}$, the unit energy efficiency ratio is 3.85 , and the system energy efficiency ratio is 2.39 ;

When the medium flow rate at the evaporator side is $240.73 \sim 244.61 \mathrm{~m}^{3} / \mathrm{h}$, the energy efficiency ratio of the unit is 4.16 , and the energy efficiency ratio of the system is 2.76 . The energy efficiency ratio of the unit is also high and stable.

The conclusion is as follows: under the heating condition, the suitable range of medium flow at evaporator side of air conditioning unit is $240.73 \sim 244.61 \mathrm{~m}^{3} / \mathrm{h}$. At this time, the medium temperature difference at the inlet and outlet of evaporator side is $1.5^{\circ} \mathrm{C}$, the unit energy efficiency ratio is 4.16 , and the system energy efficiency ratio is 2.76 .

\subsection{Influence of Medium Flow Rate at Condenser Side on Water Source Heat Pump System}

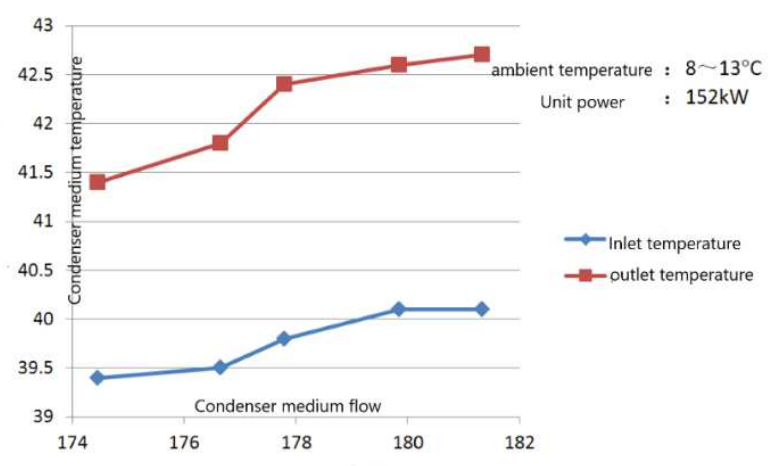

Figure 1. Influence of medium flow rate at condenser side on temperature difference. 


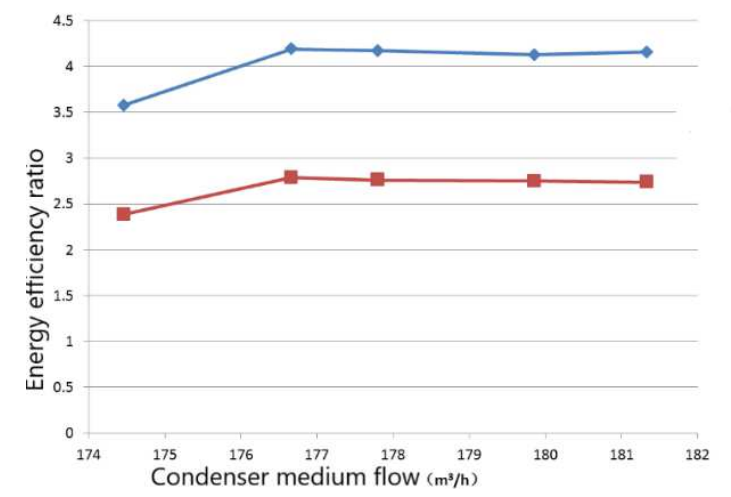

Figure 2. Influence of medium flow rate at condenser side on system energy efficiency ratio.

It can be seen from Figure 2 that in the heating condition of screw type water source heat pump air conditioning system, the relationship between the medium flow at the condenser side of screw type water source heat pump and the medium temperature difference at the inlet and outlet of the condenser side of screw type water source heat pump air conditioning unit is that the temperature fluctuation of the medium (air conditioning water) at the outlet of the condenser side is small, and the medium temperature at the inlet and outlet of the condenser side increases with the increase of the medium flow at the condenser side When the mass flow rate is $177.79 \sim 181.33 \mathrm{~m}^{3} / \mathrm{h}$, the outlet medium temperature of condenser side tends to be stable. The temperature difference between the inlet and outlet medium of the condenser side of screw type water source heat pump air conditioning unit decreases with the increase of the medium flow rate of the condenser side.

When the medium flow at the condenser side is $174.46 \mathrm{~m}^{3} / \mathrm{h}$, the temperature difference between the inlet and outlet medium at the condenser side is $2^{\circ} \mathrm{C}$;

When the medium flow at the condenser side increases by $176.66 \mathrm{~m}^{3} / \mathrm{h}$, the temperature difference between the inlet and outlet medium at the condenser side is $2.3^{\circ} \mathrm{C}$;

When the medium flow rate of condenser side is $177.97 \sim 181.33 \mathrm{~m}^{3} / \mathrm{h}$, the temperature difference between the inlet and outlet medium of condenser side is about $2.6^{\circ} \mathrm{C}$, which tends to be stable.

According to figure 3 , when the medium flow rate at the condenser side is $174.46 \mathrm{~m}^{3} / \mathrm{h}$, the energy efficiency ratio of the unit is 3.85 , and the system is 2.39 ;

When the medium flow at the condenser side increases to $176.66 \mathrm{~m} 3 / \mathrm{h}$, the energy efficiency ratio of the unit and the system is 4.19 and 2.79 respectively;

When the medium flow rate at the condenser side is $177.97 \sim 181.33 \mathrm{~m}^{3} / \mathrm{h}$, the energy efficiency ratio of the unit is high and stable. At this time, the energy efficiency ratio of the screw type water source heat pump unit is 4.16 , and the energy efficiency ratio of the system is 2.76 .

The conclusion is as follows: under the heating condition, the suitable range of medium flow at the condenser side of air conditioning unit is $177.97 \sim 181.33 \mathrm{~m}^{3} / \mathrm{h}$. At this time, the temperature difference between the inlet and outlet medium at the condenser side of air conditioning unit is $2.6^{\circ} \mathrm{C}$, the unit energy efficiency ratio is 4.16 , and the system energy efficiency ratio is 2.76 .

\subsection{The Influence of Heating Time on the Operation of Open Water Source Heat Pump Air Conditioning System}

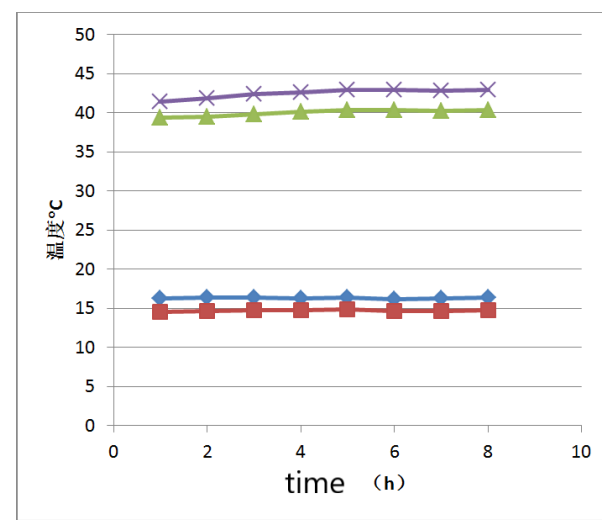

Figure 3. Relationship between system operation time and medium temperature at inlet and outlet of evaporator side and condenser side.

Figures 3 shows the temperature change of the medium inlet and outlet at the condenser side and evaporator side of the air conditioner in the eight hours of normal operation of the administrative center every day under the heating condition. According to 4.1.1 and 4.1.2, the best medium flow at the evaporator side is $240.73 \sim 244.61 \mathrm{~m}^{3} / \mathrm{h}$, and the best medium flow at the condenser side is $177.97 \sim 181.33 \mathrm{~m}^{3} / \mathrm{h}$. At this time, adjust the medium flow at the evaporator side to $240 \mathrm{~m}^{3} / \mathrm{h}$ and the condenser to $180 \mathrm{~m}^{3} / \mathrm{h}$. (at this time, the flow data is still within the best flow range). When the temperature curve of the medium inlet and outlet at the evaporator side changes with time, it can be seen that during the operation of screw type water source heat pump system, the medium temperature at the inlet of the evaporator side basically fluctuates in a small range up and down at $16.3^{\circ} \mathrm{C}$, which proves that the change range of the lake water temperature is not large, and the stability of the lake water source temperature is the premise and guarantee for the system to obtain energy stably. In these eight hours, the medium temperature at the outlet of the evaporator side also fluctuates slightly up and down at $14.7^{\circ} \mathrm{C}$. With the change of time, the medium temperature at the inlet and outlet of the condenser side will basically rise slightly in the first three hours of the start-up. Although the medium temperature at the inlet and outlet rises slightly, it is guaranteed that the medium temperature does not exceed the range of the normal operation of the unit during the whole operation period, the fluctuation range of medium temperature is not large, and the temperature difference between the medium inlet and outlet is kept at about $2.6^{\circ} \mathrm{C}$. As can be seen in Figure 1, under the heating condition, the heat provided by the lake water source completely meets the heat load requirements of the administrative center, and the operation state reaches a stable state. 


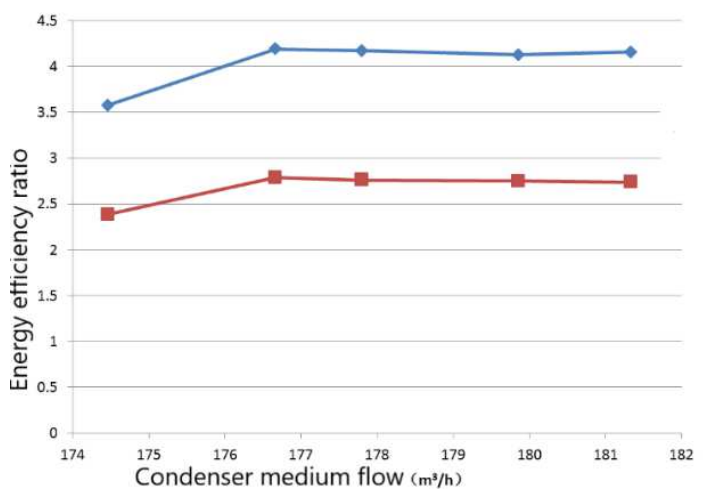

Figure 4. Impact of system operation time on system energy efficiency ratio.

It can be seen from figure4 that under the heating condition, during the eight hours of operation, the energy efficiency ratio of the system unit and the energy efficiency ratio of the system do not fluctuate greatly, which confirms the stability of the system. It can be seen from the calculation results of the unit energy efficiency ratio and the system energy efficiency ratio that the screw type water source heat pump unit meets the heating requirements of the cultural and Art Center in winter.

\section{Conclusion}

Based on the research and analysis of the operation strategy and operation characteristics of the water source heat pump air conditioning system of Chongzuo water source heat pump energy station independently designed by the research team, this paper provides reference for the application research of the open water source heat pump air conditioning system in office buildings and comprehensive venues. After a series of research and analysis, the following conclusions are drawn:

According to the relevant data of Chongzuo culture and Art Center and administrative center, the system design scheme of screw type surface water source heat pump unit, water-cooled screw type water chiller combined refrigeration and screw type water source heat pump unit heating is proposed.

The single factor method is used to study the system under heating condition, and the factors that affect the system (environment temperature, unit operation time, unit condenser side and evaporator side medium flow, etc.) are studied. Through comparison, the best operation mode under heating condition is obtained. From the experimental results, the water source heat pump system has been in a stable and efficient operation state.

Under the heating condition, the operation parameters of the screw water source heat pump system of the administrative center in winter are tested. Through the analysis of operation characteristics and data processing, the more appropriate operation scheme of the screw water source heat pump system is obtained: the more appropriate range of medium flow at the evaporator side of the air conditioning unit is $240.73 \sim 244.61 \mathrm{~m} 3 / \mathrm{h}$, at this time, the temperature difference between the inlet and outlet medium at the evaporator side is $240.73 \sim 244.61 \mathrm{~m} 3 / \mathrm{h}$ The temperature difference is $1.5^{\circ} \mathrm{C}$. The suitable range of medium flow at condenser side of air conditioning unit is $177.97 \sim 181.33 \mathrm{~m} 3 / \mathrm{h}$. At this time, the temperature difference between inlet and outlet medium at condenser side of air conditioning unit is relatively small and stable, and the temperature difference is $2.6^{\circ} \mathrm{C}$. After the above two conditions are met, the unit energy efficiency ratio and system energy efficiency ratio can reach the highest and most stable state. The unit energy efficiency ratio is 4.16 , and the system energy efficiency ratio is 2.76 .

\section{References}

[1] Liu Z, Tan H, Li Z. Heating and Cooling Performances of River-Water Source Heat Pump System for Energy Station in Shanghai [J]. Procedia, 2017, 205: 4074-4081.

[2] Wenjing W U, Wang D, Chenfei Q U, et al. Application of Automatic Control Technology in Electrical Design of Sewage-Source Heat Pump Energy Supply Station [J]. Modeen Architecture Electric, 2017.

[3] ZHANG Z, ZHOU Z, YANG M, et al. Operational effect of ground source hear pump in integrated energy station [M]. 2015: 3023-3027.

[4] MASTRUCCI A, MARVUGLIA A, LEOPOLD U, et al. Life cycle assessment of building stocks from urban to transaction scales: a rebiew $[\mathrm{J}]$. renewable and Sustainable Energy Reviews, 2017, 74: 316-332

[5] Na Wei, Wang Han, Hou Jing, Wu Yong. Area data analysis of public buildings and industrial buildings in China based on Taylor series neural network method (1) [J]. HVAC, 2017, 47 (11)

[6] Ma zuileng, Yao Yang. Air conditioning design of civil buildings [M]. Beijing: Chemical Industry Press, 2010.

[7] Li Deying. Heating engineering: China Construction Industry Press, 2004.

[8] Kavanaugh S P, Pezent M C. Lake water applications of water-to-air heat pumps [J]. ASHRAE Transactions, 1990, 96 (1): 813-820.

[9] ASHRAE. Systems and equipment handbook (SI). Atlanta: American Society of Heating, Refrigerating, and, AirConditioning Engineers, Inc. 1992, 173-176.

[10] Xu LingHong, Lu Qionghua, Hu Pingfang, et al. Study on the economy of water loop heat pump air conditioning system [J]. Fluid machinery, 2008, 36 (2): 69-73.

[11] ALLEN J J, Hanmilton J F. Steady-state reciprocating water chiller models [J]. ASHRAE Transactions, 1983, 89 (2): 398407.

[12] Ma Hongquan, long weiding. Application of water source heat pump and water thermal pollution [J]. HVAC, 2009, 39 (07): 66-70.

[13] Wang Guiling, Liu Yun, Lin Wenjing, Li Yuanjie, Shi Yongxia. Study on applicability evaluation index system of ground water source heat pump [J]. Urban geology, 2011, 6 (03): 6-11. 
[14] Di Yanqiang, Wang QingQin, Yuan Dongli, Huang Tao. Application and development of water source heat pump [J]. Refrigeration and air conditioning, 2006 (05): 1-4.

[15] Xu Wei, Wang Guiling, Zou Yu, sun Zongyu, Li Ji. Study on the technical suitability of ground water source heat pump in China [J]. Building science, 2012, 28 (10): 4-8.

[16] Zhang Zhaohui, Wang Ruonan, Gao Yu, Liu Huicheng, Liu Lulu, Bai Junwen, Chen Jingliang. Application status and development prospect of heat pump technology [J]. Refrigeration and air conditioning, 2018, 18 (01): 1-8.

[17] Zhang Jun. development status and problems of surface water source heat pump [J]. Refrigeration, air conditioning and electric machinery, 2007 (06): 73-77.

[18] Zhang Xian, Qin Xiaorong, Duan Kaiqiang, Liu Hao, Chen Shuai. Investigation and energy efficiency analysis of low temperature heat source of water source heat pump unit $[\mathrm{J}]$. Shanxi science and technology, 2018, 33 (01): 112-115.

[19] Shenghua Zou, Xiaokai Xie. Simplified model for coefficient of performance calculation of surface water source heat pump [J]. Applied Thermal Engineering, 2017, 112.

[20] Qu Honghu. Application analysis of water source heat pump air conditioning system in an office building in Beijing [J]. Jilin water conservancy, 2017 (12): 60-62.

[21] Wang Fang, fan Xiaowei, Zhou Guanghui, Lian Zhiwei. Research status of water source heat pump in China [J]. Fluid machinery, 2003 (04): 57-59.

[22] Wang Jiqing, Zhang Bailiang. Application of water source heat pump in greenhouse heating [J]. China agronomy bulletin, 2005 (06): 415-419+442.

[23] Tanveer Ahmad, Huanxin Chen, Jan Shair. Water source heat pump energy demand prognosticate using disparate datamining based approaches [J]. Energy, 2018, 152.
[24] PEER T, JOYCE W S. Lake-source cooling [J]. ASHRAE Journal, 2002, 44 (4): 37-39.

[25] Cai Jun, Chen Jiaocai, Chen Xiaojun, et al. Design of water source heat pump control system based on greenhouse prediction model $[\mathrm{J}]$. Journal of instrumentation.

[26] Stefanuk N B M, Aplevich J D, Renksizbulut. Modeling and simulation of a Super heat-controlled water-to-water heat pump [J]. ASHRAE Transactions. 1992, 98 (2): 172-184.

[27] Lu canren. Heat pump and its future application in China [J]. Power machinery, 1957, (2): 57-59.

[28] ASHRAE. ASHRAE handbook-applications. Atlanta: American Society of Heating, Refigerating And AirConditioning Engineers, Inc. 1999, 794-796.

[29] Haili Zhou, Wenhe Zhou, Jianyun Wu, Zhaohui Zhou, Shiwen Ding. Measurement and Analysis of A Heating System Based on Underground Water Source Hrat Pump in Zhangye City [J].

[30] Zhiqiang Kang, Xiaoxi Zhou, Yiyang Zhao, Ruiting Wang, Xiaoyue Wang. Study on Optimizationg of Underground Water Source Heat Pump [J]. Procedia Engineering, 2017, 205.

[31] Yong Cho, Rin Yun. A raw water source heat pump airconditonging system [J]. Energy\&Buildings, 2011, 43 (11).

[32] PI Jinhai, Hu Zhi, Ao Zhaoyao, Ma Li. Hybrid application and well completion technology of shallow surface water source heat pump system [J]. China equipment engineering. 2018 (20): 218-219.

[33] Liu Zhiguang. Study on operation characteristics of small water source heat pump system [D]. Tianjin University of Commerce. 2014. 